\title{
Review of: "Acidity and sulfur oxidation intermediate concentrations controlled by O2-driven partitioning of sulfur oxidizing bacteria in a mine tailings impoundment"
}

\author{
Jianqiang $\operatorname{Lin}^{1}$ \\ 1 Shandong University
}

Potential competing interests: The author(s) declared that no potential competing interests exist.

This study reveals the environmental biochemical cycling processes in a mine tailings impoundment, including the important environmental factors ( $\mathrm{pH}$ and $\mathrm{O} 2$ ), key sulfur compounds, microbial community composition and microbial sulfur metabolism over a long spatial and temporal horizon. Results indicated that O2-driven partitioning of sulfur oxidizing bacteria could affect the acidity generation and thiosulfate persistence. The dominant flora in circumneutral mining waters was involved in four chemolithoautotrophic sulfur-oxidizing bacteria, and the sulfur metabolism characteristics of these bacteria were also revealed by RNA-seq. This research provides a comprehensive and systematic knowledge on the process and pattern of environmental biochemistry cycle of sulfur in the circumneutral mining waters. However, there were some defects and deficiencies that need to be improved. Some examples are as the followings:

1. Some important information should be added in the introduction section, such as the significance and value of the research on the circumneutral mine tailing impoundments, the researches on microflora in mine tailing impoundments, the chemolithoautotrophic sulfur-oxidizing bacteria and their functions in sulfur cycle.

2. "Thiobacillus" has previously been associated with several types of sulfur-oxidizing microorganisms that were reclassified by Kelly and Wood in 2000. Thus, the genus of Thiobacillus should be clearly defined in this manuscript.

3. There is lack of literature support about some information in the introduction section, such as "Autotrophicsulfur oxidizing bacteria that express these pathways may also have the capacity for aerobic respiration and/or denitrification, thus $\mathrm{O} 2, \mathrm{NO3}$ - and other oxidized $\mathrm{N}$ compounds are plausible terminal electron acceptors for Sox,rDSR and S4I pathways. "

4. There maybe an mistake about "Figure3c" in this sentence " Bray-Curtis Cluster and non-metricdimensional scaling (NMDS) 3-dimensional analysis revealed three temporal clusters for both microbial community structure and metabolic capability (inferred by gene relative abundance; Table S5 (Figure 3c)". 5. The "4" in "the (S4I) pathway" should be subscripted. 
